\title{
Artistic Action and Stop Motion Animation for Preschool Children in the Particular Context of the Summer Camps Organized by the Athens Open Schools Institution: A Case Study
}

\author{
Christina Palaiologou \\ Department of Early Childhood Education and Care \\ University of West Attica, Athens, Greece \\ Eleni Tsampra \\ Department of Graphic Design and Visual Communication \\ University of West Attica, Athens, Greece
}

\begin{abstract}
In the last few decades, workshop animation has greatly contributed to the artistic expression of preschool children. The ways of development and the methods that are used each time in a workshop vary depending on the case. In this study, it is particularly interesting to note that at this specific workshop animation, 50 children of different ages and nationalities, from different regions of Athens participated during the summer. The reactions of 25 children aged 5 to 6 years and the way of working with older children were taken into consideration and examined. This action took place within the Open Schools programs, an institution that offers free creative participation to children who, due to financial problems because of the economic crisis, were unable to leave Athens in the summer and/or pay similar private institutions. Despite the exceptionally difficult circumstances preschool children were able to follow the stop motion animation process they played, had fun and created their own movie.
\end{abstract}

Keywords: workshop animation; preschool children's education; art; New Technologies; aesthetic education.

\section{Introduction}

In recent decades preschool children's education in Art and New Technologies has been the subject of many studies (Havelock, 1982; Lanham, 1993; Bijvoet, 1997; Gregory, 1997; Wartella \& Jennings, 2000; Harvey, Skinner, \& Parker, 2002; Duncum, 2003; Facer, Furlong, Furlong, \& Sutherland, 2003; Holloway \& Valentine, 2003; National Research Council, 2003; Duncum, 2004; Krug, 2004; Sweeny, 2004; Tavin \& Hausman, 2004; Taylor, 2004; Ito, 2005; Smith, 2005; 
Wilson, M. 2005; Bruce, 2007; Marmé Thompson, 2007; Sefton-Green \& Soep, 2007; Wilson, B. 2007; Webster, 2007; Snyder \& Bulfin, 2007; Ko \& Chou, 2014; Liua, Toki, \& Pange, 2014). In the present work, the findings of these studies are examined through Greek and foreign literature to investigate the case of Open Schools, a new institution created in Athens the last two years to address issues arising from the economic crisis. It is well-known that children aged 5 to 6 move comfortably, feel safe, exercise and develop the skills they possess and constantly acquire new ones (Zakopoulou, Kakaroglou \& Kosma, 1993, pp. 4950). Up to six years they perfect all the stages of the kinetic sequence and are thus able to perform an action at their best (Dolyopoulou, 2009, pp. 301-302, p. 304). At this age, children can work with other children and follow rules more easily because they can better establish relationships with their friends or their games (Dolyopoulou, 2009, pp. 308-310).

Their participation in an artistic activity can help them develop new skills that will enhance their self-confidence and lead them to successfully face future challenges. Undoubtedly, these artistic activities should be planned and organized in such a way as to contribute to the proper development of children according not only to their age, but also to their needs and desires. Scientific research from the field of pedagogy, psychology, neuroscience and art emphasizes the important role of aesthetic education in children's development (Dewey, 1982, p. 346, p. 362; Chapman, 1993; Bresler, 1994; Thompson, 1995; Kindler, 1996; Piscitelli, 1996; Schirrmacher, 1998; Matthews, 1999; Wright, 2000; Papadopoulou \& Fragkoulis, 2018). Hence through visual arts (drawing, painting, plastic, collage, etc.), children produce a variety of visual forms capturing at the same time their thoughts and feelings. An artistic activity leads children to creation, fosters interest, imagination and memory, stimulates the enrichment of knowledge and experience and contributes to their socialization. Any kind of experimentation and discovery, through play, contributes to the child's full development (Dolyopoulou, 2002, p. 37). In addition to the aesthetic experience offered by Art, children have the opportunity to discover forms and techniques of the arts (Pedagogical Institute, 2011, pp. 258-290). In the new educational programs of preschool education, the Arts sector includes not only visual arts, but also theatre, music, dance and audiovisual artistic expression. Audiovisual arts activity requires the creative use of audiovisual media and tools through play (Theodorides, 2012, pp. 103-112). This category contains forms of contemporary artistic expression, including photography, cinema, animation techniques, computer graphics, and virtual reality installations. All these forms share their creative expression through the use of computers. The power of static or moving image is undeniable. The concept of literacy is broadened and includes visual literacy (Kress \& Van Leeuwen 2001; Kress, 2003), which is defined as the ability not only to read, interpret and use visual forms related to visual communication (Kress \& Van Leeuwen 2001, pp. 15-16), but also to evaluate and create visual concepts and to produce visual messages. It is, therefore, generally accepted that the introduction of New Technologies in education and, in particular, in preschool aesthetic education is very important as it contributes to children's creative expression. Most studies concern the artistic activity of children (preschool and school age) in kindergartens, primary schools or organized animation workshops. The present study was conducted in 
a particular environment, which does not have the characteristics of the previous ones. That is, in the specific program $A$ year in a suitcase, the children didn't know each other, coming from different neighbourhoods of Athens, and they had to share this experience with older children (up to 12 years of age) for eight hours (8:00 am - 4:00 pm) from Monday to Friday during summer. Furthermore, the main goal of the Open Schools institution, which included the $A$ year in a suitcase program, was to provide a safe environment for the children whose parents were at work. This eight-hour-daily experience included a lot of artistic activities and play. The most important question in the present research must focus on the degree of responsiveness and the way in which preschool children behave and react in a program that has been held under particular circumstances. It should be noted that all the activities implemented during this program were based on play. Moreover, the goal of this institution was to creatively work with children through play.

Abundant research has shown that play during early childhood is necessary if humans are to reach their full potential. Parents, teachers and government bodies all recognize the value of play. Through play, children explore and learn the rules and symbols of their communities (Else, 2009, pp. 44-45). Because of its significance in development, play may provide a foundation of fairness and cooperation that is advantageous to communal living (Goldstein, 2012, p. 33). Fisher notes:

"Through play, children recreate roles and situations that reflect their socio-cultural world, where they learn how to subordinate desires to social rules, cooperate with others willingly, and engage in socially appropriate behaviour. Over time, these competencies are transferred to children's everyday behaviours." (Fisher et al., 2011, p. 348).

Yet opportunities for play continue to diminish, with fewer play spaces, less freedom to roam outdoors, and decreasing school time for free play (Guldberg, 2009).

\section{Art and New Technologies (ICT) in Preschool Age}

In the constantly changing society characterized by revolutionary developments in science and technology, the need for the use of ICT in education becomes of utmost importance in order to better address the challenges of modern education (Vrasidas, Zembylas \& Petrou, 2005, pp. 35-58). Some activities regarding children education may include: get to know the artist through internet research; explore new imaging technologies such as digital cameras, scanners, imaging software, printers and computers; create animation in the classroom; create and study visual music; produce digital videos; integrate digital art with fantasy/science fiction; and share poetry in online libraries. The involvement of children in an educational program on visual arts and modern artistic audiovisual works is particularly important, keeping, however, in mind that technology should not just be for show; it should have a purpose. The crucial point for the success of a program is to make it correspond and meet children's own needs and desires, so that their perceptions, feelings and thoughts are triggered by immediate experiences. At that time only children's past experiences and knowledge are recalled and observation, imagination, reflection and invention are employed (Chapman, 1993, p. 55, p. 142). In the New Cross-curricular Framework of Study Programs, in Greece, it is proposed 
to link computer science to visual arts directly in preschool education, emphasizing the direct connection of computer science to arts such as cinema and animation. Linking New Technologies to visual arts does not mean that the goal is to replace the traditional way of creating images. As Bertram C. Bruce notes "art and technology are not competing, not antitheses, and not irrelevant to one another. Nor is their essence in being not-the-other. Whatever else they may be, they are ways that people make sense of experiences and create opportunities for enlarged experiences in the future" (Bruce, 2007, p. 1359). New Technologies will be the tool for the development of new learning and creative settings. The role of New Technologies in the teaching of art is important if we keep simply in mind that the aims of art education are achieved through aesthetic experiences (Karathanasi \& Papaefthimiou, 2010, pp. 1-10). The New Technologies (Fisher et al., 2011; Guldberg, 2009), therefore, offer children aesthetic experiences in a short range of time, while at the same time, children are given the opportunity to become creators themselves and to approach new types of art such as animation (Royle, 1989, pp. 171-187). An audiovisual product follows concrete steps to its completion. These steps are the so-called technical codes, such as sounds, colours, camera, and so on. The only way for preschool children to familiarize with these new codes is by participating in playful actions.

\section{Animation Workshops in Greece: A brief presentation}

The Animation Workshop for children and youngsters has shown up in Europe and America since the 1960s. The workshop was usually organized by an artist in order to reveal the charm of this art. In this way, artists attracted new viewers and influenced new artists to express themselves through animation. The growing number of children who participated in these workshops, the excitement they felt, the way children approached even social issues and the results from animation workshops proved that children could respond very well at all stages of the process. Since the 1960s, it was considered that the inclusion of animation workshops in educational programs would offer a lot to children (Mallery, 1968). The beginning was made by the Yellow Ball Workshop, created in the US by Yvonne Andersen in 1963 (Jackson, 1997, pp. 15-18).

Today animation workshops are organized around the world by ASIFA (International Animated Film Society) as well as by schools, studios, filmmakers and professional animators in schools, camps, libraries and centres for the support of vulnerable groups. In these workshops the children-creators are taught the history, as well as the techniques of animation, while they are given the opportunity to express themselves through this art.

In Greece, some animation workshops for children are organized with traditional techniques, primarily. We can also find them in film productions or in animation festivals and meetings for the artistic expression of children and young people. Examples include workshops at the European Youth Leaders Meeting (Delphi, 1992), at the European Youth Meeting on artistic creation (Porto Germeno, 1992) regarding the representation of Greece in the Children's Biennale of Italy (Pisa, 1992) and at the International Animation Film Festival in Athens. In addition, children's films, which participated in the competition section, featured in the Kids for Kids Festival, which was organized for the first 
time in 2003 by the European Children's Television Centre (ECTC), the ECFA and the International Children's Film Centre (CIFEJ) during AGORA 2003. The children could compete with animation, live-action movies, documentaries and video clips. It is worth noting that the children competed on the basis of their age. The Olympia International Film Festival for Children and Young People (n.d.) was created in 1997 as the result of the collaboration between the Local Authorities of the region of Ilia and Youth Plan, a non-profit organization. It is supported and sponsored by the Ministry of Culture and the General Secretariat of Youth. In this festival, there are Greek and international cinematographic workshops as well as other workshops (directing, editing, sketch, animation, puppetry, painting, collage, clay, mask making, etc.) so that children and young people have the opportunity to express themselves creatively. The European Animation Centre (n.d.) is a non-profit and a non-governmental organization that aims to bring the younger generation closer to the secrets and fascination of the art of animation and their diverse applications on the small and big screen, the multimedia, the Internet and education in general. Moreover, animation workshops are organized in Greece by teachers or in workshops by professional animators. Workshops are also organized, involving children and young people from vulnerable social groups.

\section{The present research}

This study concerns the artistic program A year in a suitcase, as part of the Open Schools institution. It took place in 3 schools of the City of Athens in July 2018. The Open Schools program is an innovative initiative run by the City of Athens, which has grown popular within the local community since 2016. Schools are open to the neighbourhood and to the society. The school premises turn into meeting places and centres of action where the local community is invited to take part in recreational, cultural, educational and sports activities. Believing firmly that extroversion and creativity are choice, 25 school buildings in the city of Athens remained open during the summer (June-July 2018). Schools remained open with security from 8:00 am to 4:00 pm on weekdays and turned into meeting places for children in the neighbourhood, hosting free cultural, educational, entertainment, sports and technology activities. This program was implemented with the exclusive donor of the Stavros Niarchos Foundation and the coordination of the Athens Partnership (Athens Open Schools, n.d.). Through the Open Schools program, the City of Athens transforms school buildings into centres of culture and skills development, setting the emphasis on the child, especially on infants and toddlers. The aim is to socialize and upgrade the quality of their lives.

The actions carried out within this institution were many, various and diverse. The children could participate in any actions they wanted. The artistic action $A$ year in a suitcase was among them and it is the subject of this survey. Three educators, a drama teacher, a musician and a designer performed this action in schools in the City of Athens. The action lasted one week (2 to 6 July 2018) in the first school and was repeated in two other schools always on a weekly basis (9 to 13 July and 16 to 20 July respectively) for 8 hours a day (8:00 am to 4:00 pm). Activities took place either in the available school classrooms or in the yard. During the operation of the program there were both security staff and ancillary 
staff members (cleaners) at the school. The age of the 50 children who participated in this program varies from 5 to 12 years. 25 among them were preschool children 5 and 6 years old. As resulted from both the application (in the beginning) and the evaluation forms (at the end of the program) completed by the participants' parents, the main reason of the children's involvement in these summer actions was primarily due to the parental need of a safe place to leave their children in their working hours. On the other hand, several parents added that they would like their children to be more sociable, interact with their peers and become more creative. The central issue of the artistic action $A$ year in a suitcase was based on the children's will and ability to create both objects and environments from their experiences and reminiscences of the past school year through collaboration, individuality, fantasy and desires. The final product was the creation of a suitcase (to take away) in which they put all their creations during the action. In this program, the children had the opportunity to express themselves through singing, drama activities, games (both individually and in teams), painting, clay, collage and stop motion animation. The actions that have been carried out have followed the principles of modern pedagogy, the utmost goal of which is to link school with society and real life (Dewey, 1982, pp. 33-51). Thus the whole action has been prepared, designed and projected taking into consideration various important factors: the location (school premises during summertime), the acquaintance and contacts of the children, initially unknown to each other, who came from different Athenian schools (different school experiences), of different ages (5-12 years), of different social strata and of various nationalities. All these parametres should coexist in an 8-hour time range daily, from Monday to Friday. The collaboration among children should respond to the demands of child-centred education (Klafki, Meyer, \& Weber, 1981, pp. 20-25) and enable the participants to develop initiatives, to help others and themselves and be helped (Meyer, 1995, pp. 82-83). The opposing views and controversies that may emerge through collaboration may increase the interest of children, and often children can be led to solve problems in a variety of ways (Gonschorek \& Schneider, 2000, p. 38). It is worth noting that during this action the children were not obliged to follow the structure of a formal school curriculum. They came voluntarily to the summer camp, participated in the artistic activities they chose, and were able to play freely in small groups or on their own.

A significant activity in the present program was stop motion animation workshop. Children were particularly interested in this activity, they attended it at all stages of its development, from the beginning to the production of the short film they produced. In this particular activity, research, experience gaining, creation and social interaction played a special role. For these reasons, the present research will be based on the activity of stop motion animation and will represent the whole artistic action.

\section{Methodology}

This study took place in one of the three schools where the A year in a suitcase program was held and it will investigate the reactions of 25 children aged 5 to 6 who participated in the workshop animation and, more specifically, the way in which children responded to the different stages of the artistic activity. It will 
also examine the relationships developed among children of the same age as well as their relationships with older children ( 25 children, 7 to 12 years) who shared the same experience. Finally, the relationship between children and educators during the action will be examined. The above research questions will be answered through the case study, as this research has a goal it has time and space limitations, functional parts and its own identity. The case study has its own research design (Stake, 1995, pp. 51-53; Bassey, 1999, pp. 66-73; Shaw, 1999, pp. 135-138; Robson, 2002; Cohen, Manion, \& Morrison, 2008, p. 323; Mertens, 2009). In this work, the intrinsic case study (Stake, 1995) was adopted, since it focuses on a specific group, an event and relates to an institution, while the research interest stems from the researchers' need to learn as much as possible about the specific case. In addition, this study will take into consideration the well known theories, such as play-based learning (Piaget \& Inhelder, 1969), social interaction - constructivist theory (Vygotsky, 1978) and multiple intelligences theory (Gardner, 1993).

Among other objectives, especially within the stop-motion animation workshop, there was the objective of providing children with a playful educational and artistic experience where they could interact with each other, explore new ways of expression and have the challenge and the ultimate fulfilment of having solved a problem. In the following sections, the educators' teaching approach and strategies will be described, the specific conditions under which the animation workshop was developed as well as its outcomes. As mentioned before, the young participants originated from different environments (neighbourhoods, schools), therefore they were unfamiliar with the activities, did not know the educators nor their peers, a fact which surely added a certain level of difficulty to the realization of the whole attempt.

\section{Thinking about the problem}

The problem-solving approach was adopted. Initially, the problem was set and planned: each child should create a clay character. After that, children should form small groups of three or four people, so that each group could construct a custom-made scenery - environment out of waste materials that would host their characters. Then, each group in their own scenery should perform with their characters an act of their choice and eventually all shots would be edited in order to form a film, a school-wide art project called $A$ year in a suitcase. In that way, children were expected to perform several individual activities, such as designing or modelling and cooperating in front of and behind the camera, in order to direct their shots.

The level of skill and the techniques required for the above activities were generally, developmentally appropriate; however, certain tasks like directing, handling the camera, the digital equipment and the stop motion software were slightly above their present abilities. The very essence of stop-motion technique, which requires the gentle movement of objects, slowly and orderly behind the camera, demands fine motor skills, coordination of movements, attention, extreme concentration and patience that some children of this age may lack. Vygotsky's social constructivist theory claims that "children confronted with a problem that is slightly too complicated for them exhibit a complex variety of responses including direct attempts at attaining the goal" (Vygotsky, 1978, p. 
30). He believed that children through imitation "are capable of doing much more in collective activity or under the guidance of adults" (Vygotsky, 1978, p. 88) and that "learning awakens a variety of internal developmental processes that are able to operate only when the child is interacting with people in his environment and in cooperation with his peers" (Vygotsky, 1978, p. 90). Thus, several activities, requiring a high level of digital literacy, such as handling the animation software, were accomplished with the educator's guidance, others such as organising the moves of the objects, were done with the assistance of older peers (7-12 years).

\section{Introducing the game}

In a game there are rules. Rand notes:

"Without the basic rules or disciplines, however, there is no motivation, test of skill, or ultimate reward - in short, no game. The rules are the means to the end, the conditions the player must understand thoroughly and work with in order to participate." (Rand, 1965, p. 156).

"Limited means", says Braque, "beget new forms, invite creation and make the style. Progress in art does not lie in extending its limits, but in knowing them better" (Braque, 1947, p. 33).

On the first day, a simple, abstract shape on the whiteboard was designed. The children were asked what they thought it was like. Through brainstorming, several answers followed: it was "a cloud" (Nefeli, 5), "a map" (Electra, 6), "a bin" (Iris, 5). Later on, a detail looking like "an eye" was added. What was it now? Since this shape was somewhat anthropomorphized, the given answers were more relative to animate objects or animals: it was "a fish" (Tasos, 5), "a snake" (Gabriel, 5).

Following these comments, several elements were added, most of them playfully demanded by the children: a nose, a tail, two long thin legs, then a third short one, an earring, a tattoo, a hat, a skirt, a ponytail, lips, a wing, a boot and a pair of sneakers. What was it now? According to Maria (6), it was "certainly a flamingo". By observing it further, children provided other answers which included "a cat" (Michaela, 5), "maybe a boy or a girl" (Vasilis, 5) or "both" (Antonia, 6). These words were noted on the whiteboard. Then the children started combining words like "a flamingo-cat", which gradually became more and more complex: it was "a flamingo-cat-girly-sneaky-boy dog..." Eventually, George (6) came with a more abstract answer: "It is a fantastic animal". Most of his peers seemed to agree, so these two last words were written on the whiteboard.

After sticking to George's answer, and adding that it could be a character out of a book or an animated film, it was suggested they could simplify it, to keep only two or three of these extra formal characteristics they had added during the sketching procedure. They erased some lines and rearranged some others. After that, an educator grabbed a ball of coloured clay and described her intention: with their guidance, she would try to transform the sketch they had just made to a three dimensional object. She started with a main colour of clay and a simple ball. She squeezed it, altered its form repeatedly and opened a hole on with her finger. One by one, the children could touch, examine and observe the material she was holding. 
Then, the children selected two different colours of clay in smaller quantities. Step by step and without the assistance of any modelling tools, they added elements on the clay ball, based on the design on the whiteboard. Finally, there was it: a three dimensional fantastic animal.

\section{Setting the rules of the game. Ready to play?}

This demonstration certainly acted as an ice-breaker activity. Far from methods and views of pedagogists such as Derham (1961) or Brownlee (1983), who are both rigid in prescribing the role of the adult: "[...] we never draw, make or model for the child" (Terreni, 2010, p. 6), the educator took the initiative to sketch and model not for but with the children. Her intent was not to limit children's creative potential, but to start a conversation with them instead, not only about the particular activity she was demonstrating but about the overall nature of the project. She explained that, in order to play this game and accomplish this film, they had to follow several rules all together.

Most of the limitations were already imposed by time factors and the specific nature of the environment in which the workshop was held. Unlike the Reggio Emilia Approach (Loh, 2006) where great attention is given to the look and feel of the classroom which is often referred to as the third teacher, the classroom where the activities took place, was rather hostile. It was poorly decorated, empty of all sort of materials that could stimulate the children's interest, and rather hot, which posed a problem, since clay is extremely sensitive to high temperatures. However, the educators saw every single limit as a challenge that would evoke extra motivation and chances for improvisation. Materials had to be found, the classroom furniture had to be rearranged, and children had to invent short scenarios for the characters, in order to act really fast in front of the camera, to avoid the melting of the material as well as the fatigue especially that of the younger children.

By employing the same method through which they had co-constructed this fantastic character, each child would create his / her own later on: first they would design their idea on a piece of paper, then they would name it and, finally, they would model it.

The educator erased the sketch on the whiteboard. "Now it is your turn!" she said.

\section{Make a sketch, name it and then model it.}

According to Hester and Hannaford "asking students to write about their decisions and process helps them slow down to observe, reflect, and then react. In observing and reflecting, students also adopt a curious mindset" (Hester \& Hannaford, 2013, p. 3).

Some of the parameters given to children were: make the sketch of your character in less than ten minutes, use a marker, choose only one colour, draw it on a small blank paper $(10 \mathrm{~cm} \times 15 \mathrm{~cm})$ and name it. Time constraints were not imposed only for practical reasons; their function was also to stimulate children's attention. On the other hand, the intentional restriction in the variety of means (materials) could produce ideas. Younger children wrote down the names of their characters with the help of older peers and educators. It is worth noting that older children (aged 7-12 years) mostly preferred drawing more real 
animals or stereotyped characters, probably inspired by the widely spread images of pop-culture. In contrast, younger children's visualizations as well as their verbal explanations included real animals such as cats, dogs, fish, dinosaurs, as well as more complex characterizations such as: "a circle with feet, hands and eyes" (Melina, 5), "apple - cutter" (Foteini, 6), "owl - rabbit" (Adrianna, 6), "fish - dinosaur" (Maria, 6), "crocodile - chainsaw" (Paul, 5), "a dog with trousers" (Nikolas, 5), "a rabbit-baker" (Agapi, 6), obviously inspired by the fantastic animal previously drawn on the whiteboard.

After that, the children chose one main colour of clay, and two secondary ones of smaller quantities, in order to start modelling. However, many of them decided to exchange parts of their materials in other colours of similar quantities with each other. Next, using their sketches, they started modelling their drawings. Some of them improvised with their own techniques, others used tools such as pencils and wood sticks. Their sketches served as pre-visualizations of their ideas, introducing them to forms of artistic expression that require, apart from imagination (as it is commonly believed), organization skills, a method and analytic thinking. A general observation on the youngest children's modelling (aged 5-6 years) showed tendencies of extreme schematization, and bidimensionality of the forms.

\section{Think about an environment and construct it. Act!}

On the second day of the workshop, the children were invited to form small groups in order to construct their sceneries and animate their characters. Only two groups at a time were allowed to work in the classroom, a fact that created great anticipation to the rest of the children who had to wait for their turn, while doing other activities. Generally, there was not a time limitation regarding the creation of sceneries, it rather depended on the complexity of the sceneries and the willingness of the group to work together (from some minutes to one or two hours), while the educators were assisting them with materials and techniques. The children could look for waste materials, or use several ones left from their peers who had just shot their animation. Unorthodox materials substituted an object with another, thus developing their symbolic thought (Goldstein, 2012, p. 9): a wood with random holes became a home or a small animal, papers became waves, wadding represented clouds, a wooden cube meant a building, a book substituted a lake. The more abstract the shapes of the found objects (for example, the old piece of wood with the holes) were, the more uses and roles they shared in their decors and scenarios produced excitement to the children. Sometimes, the new team just rearranged the elements of the previous group's environment, and, there was it: a new scenery! These new decors, composed by old elements, provoked the interest of the previous groups as well, who recognized their objects used in new contexts (Adrianna, 6). Moreover, as Shklovsky noted in 1916:

"The purpose of art is to impart the sensation of things as they are perceived and not as they are known. The technique of art is to make objects "unfamiliar" to make forms difficult, to increase the difficulty and length of perception because the process of perception is an aesthetic end in itself and must be prolonged. Art is a way of experiencing the artfulness of an object: the object is not important (original emphasis)." (Shklovsky, 2004, p. 16). 


\section{Passing from the analogue to the digital part}

When the backgrounds were ready, it was time to start filming. The educators dedicated some minutes to explain several technical aspects and constraints of the stop motion technique. The transition from the analogue to the digital part of the whole procedure, which made children see their backgrounds and characters through the camera lens and on the laptop monitor, caused immense wonder and joy to all groups. Many children observed the framing of their scene through the animation software and made comments about how different everything looked now that it had been isolated from all the other elements around it (the furniture of the classroom).

Generally, younger children saw the possibilities of the software in terms of magic. They played with their hands in front of the camera, just to test the results on the monitor, and had great joy in exploring the equipment's capacities. Older children, more advanced in digital literacy, who assisted their younger peers, asked questions about the software and were acquiring new operational skills very quickly.

Due to the number of participants and time constraints, there was a specific limitation concerning the exact number of the photographs (50 altogether) taken by each group of children. In terms of real time this meant almost five seconds of action that would be stretched later by the educators through editing techniques. In order to help groups compose their short narratives and combine their characters in one act, the educators posed questions such as: where do your characters want to go? or what do they want to do? This involvement in the form of questions, comments and suggestions guided them through the whole filming procedure.

The younger children liked more the procedure itself and they were also impatient to check the result while the older ones were equally interested in storytelling. Generally, the older children came with more sophisticated solutions and complex ideas about their scenarios (Panagiotis, 8; Marisa, 8; Melina, 9) and asked questions regarding the digital manipulation of image and some creative uses of technology, while the younger ones were more interested in moving their characters or playing the role of the photographer. Worth noting is the fact that several groups decided to switch roles during the filming, while others chose one specific role (photographer, actor).

The second day of the workshop ended with each group watching and examining the result of their work on the laptop screen. There was no editing yet that is why their characters moved too fast! Each team saw again and again their cooperative, five seconds achievement. By watching the outcome of their efforts, there has not been a single one child leaving the classroom without feeling fulfilment and excitement.

On the third day, all the material was edited and projected in front of all the participants and their parents. The satisfaction for the results of their efforts was evident on the children's faces. Anna (6) commented that "among all the other activities she had participated to at the Open Schools program, animation has been the one she could not do alone at home". However, the educators explained that even with simpler means (a telephone with a camera or a non- 
professional, free-for-download software) she could achieve more or less the same results at home.

\section{Observation Outcomes / Evaluation}

A semiotic analysis regarding the morphology of the characters created by the children in this workshop, could be the subject of a different study. However, a general observation is that the ways the children treated and presented their characters reminded us of some of their personal traits. As educators, we were especially concerned to see how several children who demonstrated anti-social behaviour or had learning difficulties, would engage with the above activities. Angelos (6), a child with attention disorder and aggressive behaviour, created a robot "that would destroy everybody", as he explained while constructing it. During the animation process, he had difficulty in performing gentle moves with his character or waiting for the shot after each move. He really enjoyed breaking his character in parts. He was, nonetheless, extremely amused with the filming procedure. Worth noting is that his choice to create a robot might have been inspired by a workshop on robotics which he had attended the previous week in the same school, thus demonstrating how children's artistic experiences involve not only their personal desires, choices or fears but, also, their previous educational experiences and recently acquired knowledge in other fields.

Another major concern was the long-term nature of the animation workshop. Would children be happy to work several days on the same project or they would wait until next day to see the results of their work?

It is generally accepted by early childhood art educators that preschoolers should engage in less product-oriented activities (McArdle \& Wong, 2010) and that they should rather focus on the process of making. However, the children showed interest in all the stages of the film production, with lots of them asking the educators when and where they could revisit their shots online, in order to show them to their parents. This great anticipation was probably a product of the specific nature of the art of animation, where the result is not there as in other forms of creation like painting, but it is rather imagined or planned. Anyway, that was one of the advantages of the workshop, since it introduced children to forms of art which require a lot of preparation and planning and can incorporate the handmade into digital contexts, thus promoting not only their visual but also their digital literacy.

\section{Study limitations and suggestions for further research}

The relatively small number of preschool children ( 25 children) who participated in this action as well as the particular circumstances (several hours of work daily, children of different ages, children unknown to each other, children who were unaware of the activities included in the program) do not allow generalizations.

It is worth noting, moreover, that the sample of children whose reactions have been recorded in the present work was random.

This study could continue in other Open Schools in other areas of Athens, where the population sample would have and show different characteristics. It would be interesting in a further/separate research to examine both older children's reactions and the relationships the latter developed with preschool children. It 
would also be very interesting to study carefully and analyze the evaluation forms completed by the participants' parents. In this way, we could see how the children transferred their experiences to their parents.

\section{Conclusions}

As it has already been mentioned, the above analyzed artistic action is part of a program designed to offer free creative employment to children during summertime. Because of the economic crisis, parents cannot often give children the opportunity to attend similar activities.

It was noticed that even if the environment was completely unknown, preschool children were at ease and were able to develop relationships and work successfully with both educators and older children.

Although the action was demanding and presented some difficulties, it was fun, as it was based on play. Preschool children created according to their own aesthetics and perspectives and expressed themselves by receiving stimuli from both educators and older children. The large number of participants together with diversity did not hinder children's artistic expression.

Stop motion animation gave children the opportunity to use the computer and the camera in new and different ways in order to produce their own work, which, in this case, was the creation of a small movie. The use of ICT has been an additional stimulus for the children to express themselves.

Moreover, this action, which required planning and co-operation, helped children socialize.

Regarding the problems that have arisen during the action as well as the consequent help from the educators who have been called upon to resolve, in order for young children not only to create but also to have fun, we can say that they have both been a challenge and an inspiration for other programs in the future.

\section{References}

Andersen, Y. (1971). Teaching Film Animation to Children. New York: Van Nostrand Reinhold. DOI:10.2307/3191588

Athens Open Schools (n.d.). Retrieved from https://www.athensopenschools.gr/.

Bassey, M. (1999). Case study research in educational settings. Buckingham: Open University Press.

Bijvoet, M. (1997). Art as inquiry: Toward new collaborations between art, science and technology. New York: Peter Lang.

Braque, G. (1947). Cahier de Georges Braque. Paris: Maeght Editeur.

Bresler, L. (1994). Zooming in on the qualitative paradigm in art education: Educational criticism, ethnography and action research. Visual Arts Research, 20 (1), 1 - 19.

Brownlee, P. (1983). Magic places: A guide for adults to encourage young children's art work. Auckland: New Zealand Playcentre Federation.

Bruce, B. C. (2007). Technology and arts education. In L. Bresler (Ed.), International Handbook of Research in Arts Education (pp. 1355-1359). Dordrecht: Springer. DOI:10.1007/978-1-4020-3052-9_92

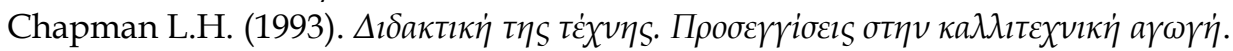
[Approaches to Art in Education]. (Trans. A. Lapourtas). Athens: Nefeli.

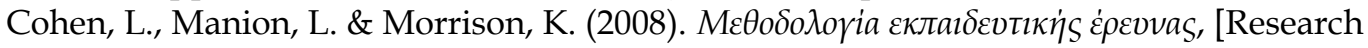
Methods in Education]. (Trans. S. Kyranakis, M. Mavraki, Chr. Mitsopoulou). Athens: Metaichmio. 
Derham, F. (1961). Art for the Child under Seven. Canberra: Australian Pre-School Association.

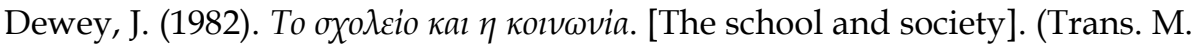
Michalopoulou). Athens: Glaros.

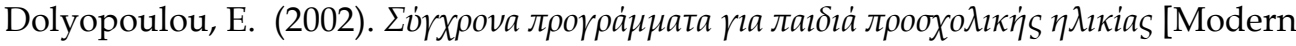
programs for preschool children]. Athens: Typotheto - George Dardanos.

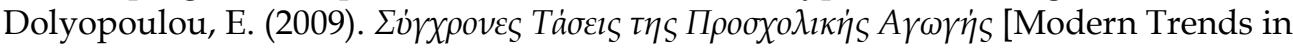
Preschool Education]. Athens: Typotheto - George Dardanos.

Duncum, P. (2003). The theories and practices of visual culture in art education. Art Education Policy Review, 105 (2), 19-25. DOI:10.1080/10632910309603458

Duncum, P. (2004). Visual culture isn't just visual: Multiliteracy, multimodality and meaning. Studies in Art Education, 45 (3), 252-264. DOI:10.1080/00393541.2004.11651771

Else, P. (2009). The value of play. London: Continuum.

European Animation Centre (n.d.). Retrieved from https://arteac.eu/about/.

Facer, K., Furlong, J., Furlong, R., \& Sutherland, R. (2003). Screenplay: Children and computing in the home. London: Routledge Falmer.

Fisher, K., Hirsh-Pasek, K., Golinkoff, R. M., Singer, D. G. \& Berk, L. (2011). Playing around in school: Implications for learning and educational policy. In A. D. Pellegrini (Ed.), Oxford Handbook of the Development of Play (pp. 341-363). Oxford: Oxford University Press. DOI:10.1093/oxfordhb/9780195393002.013.0025

Gardner, H. (1993). Multiple Intelligences. The Theory in Practice. New York: Basic Books.

Goldstein, J. (2012). Play in Children's Development, Health and Well-Being. Brussels: Toy Industries of Europe (TIE).

Gonschorek, G. \& Schneider, S. (2000). Einfuehrung in der Schulpaedagogik und die Unterrichtsplannung. Donauwoerth: Auer.

Gregory, D. C. (Ed.). (1997). New technologies in art education: Implications for theory, research, and practice. Reston, VA: National Art Education Association.

Guldberg, H. (2009). Reclaiming Childhood: Freedom and Play in an Age of Fear. Oxon: Routledge. DOI: 10.4324/9780203870419

Harvey, I., Skinner, M., \& Parker, D. (2002). Being seen, being heard: Young people and moving image production. London: National Youth Agency/British Film Institute.

Havelock, E. (1982). The literate revolution in Greece and its cultural consequences. Princeton, NJ: Princeton University Press.

Hester, C. \& Hannaford, J. (2013). The play instinct in design education. Retrieved from https://educators.aiga.org/wp-content/uploads/2013/12/hester.pdf.

Holloway, S., \& Valentine, G. (2003). Cyberkids: Children in the information age. London: Routledge Falmer.

Ito, M. (2005). Technologies of the childhood imagination: Yugioh, media mixes, and everyday cultural production. In J. Karaganis \& N. Jeremijenko (Eds.), Structures of participation in digital culture (pp. 88-111). Durham, NC: Duke University Press.

Jackson, W. (1997).Yvonne Andersen: Profile of a Pioneer. Animation World Magazine, I (12), 15-18.

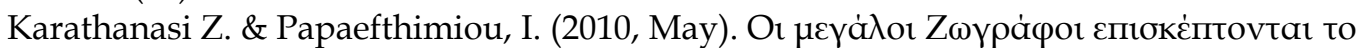

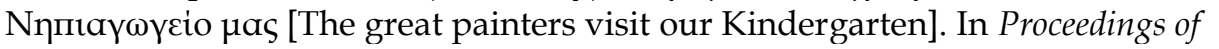

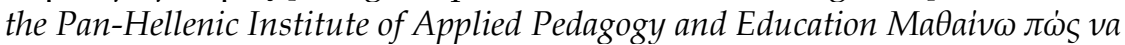
MaAaiv $[$ [I learn how to learn] (pp. 1-10). Athens: Hellenic Institute of Applied Pedagogy and Education.

Kindler, A. (1996). Artistic learning in early childhood: A study of social interactions. Canadian review of art education, 21 (2), 91 - 106.

Klafki, W. Meyer, E. \& Weber, A. (1981). Gruppenarbeit im Grundschulunterricht. [Group work in primary education]. Munich: Wilhelm Fink. 
Ko, C.-H. \& Chou, M.-J. (2014). Aesthetics in early childhood education: the combination of technology instruments in children's music, visual arts and pretend play, Journal of Social Sciences, 10 (1), 39-45. DOI : 10.3844/jssp.2014.39.45

Kress, G. \& Van Leeuwen, T. (2001). Multimodal discourse: The modes and media of contemporary communication. London: Arnold Publishers.

Kress, G. (2003). Literacy in the New Media Age. London: Routledge. DOI: $10.4324 / 9780203299234$

Krug, D. H. (2004). Leadership and research: Reimagining electronic technologies for supporting learning through the visual arts. Studies in Art Education, 46 (1), 35.DOI: $10.1080 / 00393541.2004 .11650064$

Lanham, R. A. (1993). The electronic word: Democracy, technology and the arts. Chicago, IL: University of Chicago Press. DOI: 10.7208/chicago/9780226469126.001.0001

Liua, X., Toki, E. \& Pange, J. (2014). The use of ICT in preschool education in Greece and China: A comparative study. Procedia - Social and Behavioral Sciences, 112, 11671176.DOI:10.1016/j.sbspro.2014.01.1281

Loh, A. (2006). Reggio Emilia Approach. Retrieved from http://www.brainychild.com/article/reggioemilia.shtml

McArdle, F. \& Wong, K. (2010). What young children say about art: A comparative study. International Art in Early Childhood Research Journal, 2 (1), 1-17. Retrieved from: http://artinearlychildhood.org/artec/images/article/ARTEC_2010_Research_J ournal_1_Article_4.pdf.

Mallery, D. (1968). Film in the life of the school. Boston: National Association of Independent Schools.

Marmé Thompson, C. (2007). The Culture of childhood and the visual arts. In L. Bresler (Ed.), International Handbook of Research in Arts Education (pp. 899-913). Dordrecht: Springer. DOI: 10.1007/978-1-4020-3052-9_61

Matthews, J. (1999). The art of childhood and adolescence: The construction of meaning. London: Falmer Press.

Mertens, D. (2010). Research and Evaluation in Education and Psychology. London: Sage.

Meyer, H. (1995). Didaktische Modelle. [Didactic models]. Cornelsen: Verlag Scriptor.

National Research Council of the National Academies. (2003). Beyond productivity: Information technology, innovation and creativity. Washington, DC: National Academies Press.DOI: 10.17226/10671

Olympia International Film Festival for Children and Young People, (n.d.). Retrieved from https://olympiafestival.gr/

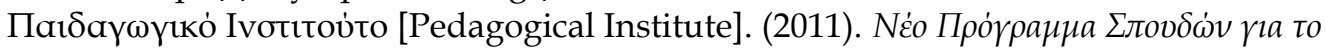

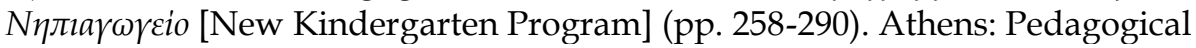
Institute.

Papadopoulou, E. \& Fragkoulis, I. (2018). The nursery teachers' views on the use of art in the education process. The case of nursery teachers of the Achaia Prefecture. International Journal of Learning, Teaching and Educational Research,17 (2), 177-200. DOI: 10.26803/ijlter.17.2.11

Piaget J. \& Inhelder, B. (1969). The psychology of the child. New York: Basic Books.

Piscitelli, B. (1996). Designing art programs for young children: lecture and workshop program. Brisbane: QUT.

Rand, P. (1965). Design and the play instinct. In G. Kepes (Ed.), Education of vision, New York: George Braziller. Retrieved from http://www.paulrand.com/foundation/thoughts_designAndthePlayInstinct/\#.W4E0wS2B0Wo

Robson, C. (2002). Real world research. (2nd ed.). Malden, MA: Blackwell.

Royle, T. (1989). Creative activities: Art and Design. In R. Crompton (Ed.), Computers and the primary curriculum 3-13 (pp. 171-187). London, New York, Philadelphia: The Falmer Press. 
Schirrmacher, R. (1998). Art and creative development for young children. Albany, NY: Delmar.

Sefton-Green, J. \& Soep E. (2007). Creative media cultures: Making and learning beyond the school. In L. Bresler (Ed.), International Handbook of Research in Arts Education (pp. 835-854). Dordrecht: Springer. DOI: 10.1007/978-1-4020-3052-9_57

Shaw, I. (1999). Qualitative evaluation. London: Sage.

Shklovsky, V. (2004). Art as Technique. In J. Rivkin \& M. Ryan (Ed.), Literary Theory: An Anthology (2nd ed.) (pp. 15-21). Malden, MA: Blackwell.

Smith, R. A. (2005). Aesthetic education: Questions and issues. Arts Education Policy Review, 106 (3), 19-32.

Snyder, I. \& Bulfin, S. (2007). Digital literacy: What it means for arts education. In L. Bresler (Ed.), International Handbook of Research in Arts Education (pp. 1296-1310). Dordrecht: Springer. DOI: 10.1007/978-1-4020-3052-9_89

Stake, R. (1995). The art of case study research. London: Sage.

Sweeny, R. (2004). Lines of sight in the "Network Society": Simulation, art education and a digital visual culture. Studies in Art Education, 46 (1), 74-87. DOI: 10.1080/00393541.2004.11650070

Taylor, P. (2004). Hyperaesthetics: Making sense of our technological mediated world. Studies in Art Education, 45 (4), 328-342. DOI: 10.1080/00393541.2004.11651779

Tavin, K., \& Hausman, J. (2004). Art education and visual culture in the age of globalization. Art Education, 57 (5), 47-52. DOI: 10.1080/00043125.2004.11653568

Terreni, L. (2010). A history of visual art education in early childhood in New Zealand. International Art in Early Childhood Research Journal 2 (1), 1-11.

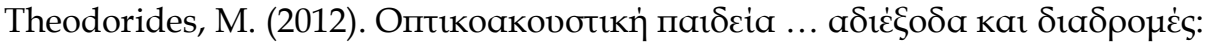

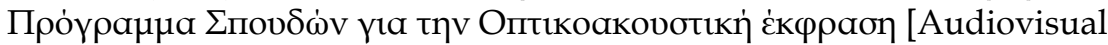
education ... deadlocks and paths: Curriculum for Audiovisual Expression]. In

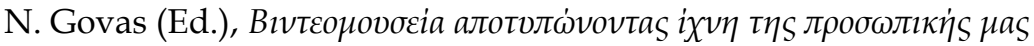

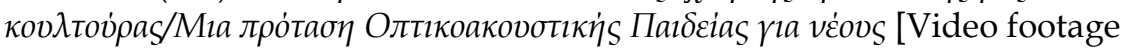
depicting traces of our personal culture/A proposal for audiovisual education for young people] (pp. 103-112). Athens: Directorate of Secondary Education of Eastern Attica.

Thompson, C. M. (1995). Transforming curriculum in the visual arts. In S. Bredekamp \& T. Rosengrant (Eds.), Reaching potentials: Transforming early childhood curriculum and assessment (Vol. 2). Washington: NAEYC.

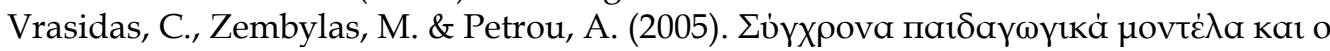

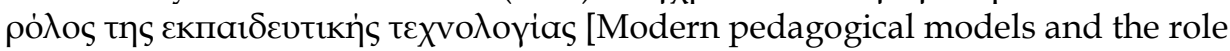

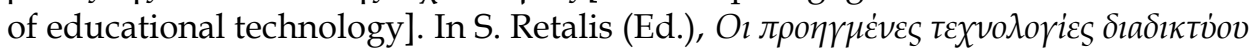

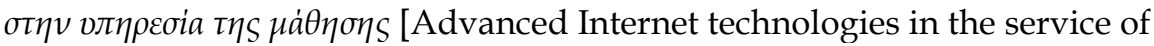
learning]. (pp. 35-58). Athens: Kastaniotis.

Vygotsky, L.S. (1978). Mind in Society: The Development of Higher Psychological Processes. (Ed. M. Cole et al.). Cambridge, MA: Harvard University Press.

Wartella, E., \& Jennings, N. (2000). Children and computers: New technology-old concerns. In R. E. Behrman (Ed.), The Future of children: Children and computer technology (pp. 31-43). Los Altos, CA: The David \& Lucile Packard Foundation. DOI: $10.2307 / 1602688$

Webster, P. R. (2007). Knowledge, skills, attitudes, and values: Technology and its role in arts education. In L. Bresler (Ed.), International Handbook of Research in Arts Education (pp. 1293-1295). Dordrecht: Springer. DOI: 10.1007/978-1-4020-30529_88

Wilson, B. (2007), A story of visual cultural and pedagogical webs. In L. Bresler (Ed.), International Handbook of Research in Arts Education (pp. 917-921). Dordrecht: Springer. DOI: 10.1007/978-1-4020-3052-9_62 
Wilson, M. (2005). How should we speak about art and technology? Crossings: Journal of Art and Technology, 1 (1). Retrieved from http://crossings.ted.ie/issues/1.1/Wilson/.

Wright, S. (2000, December). Challenging literacy perspectives. Proceedings of the 2000 Australian Association for Research in Education (AARE) Conference, Sydney, Australia. Sydney: University of Sydney.

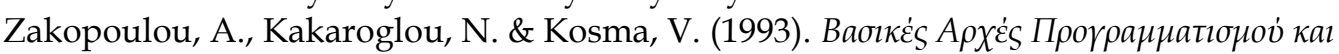

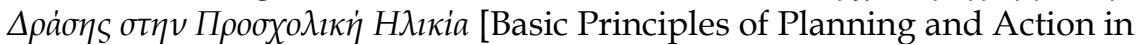
Preschool Age]. Athens: Pan-Hellenic Association of Early Childhood Educators (P.A.EC.E). 